\title{
Discrepant association of serum C-3 epimer of 25-hydroxyvitamin D versus non-epimeric 25 -hydroxyvitamin $D$ with serum lipid levels
}

\author{
La-or Chailurkit ${ }^{1,3^{*}}$, Wichai Aekplakorn², Kriangsuk Srijaruskul ${ }^{1}$ and Boonsong Ongphiphadhanakul ${ }^{1}$
}

\begin{abstract}
Background: Low vitamin D status has been associated with a number of chronic diseases. For dyslipidemia, vitamin D deficiency has been associated with higher low density lipoprotein-cholesterol (LDL-C) in a number of studies, but with inconsistent results in clinical trials. The purpose of the present study is to explore the relative importance of 3-epi-25-hydroxyvitamin D (25(OH)D) as compared with the non-epimeric form in relation to serum lipid.

Method: This study used data from 1068 randomly selected volunteers in the Thai $4^{\text {th }}$ National Health Examination Survey (NHES IV). Serum 25(OH)D $2,25(\mathrm{OH}) \mathrm{D}_{3}$, 3-epi-25(OH)D 2 and 3-epi-25(OH)D 3 were analyzed by liquid chromatography-tandem mass spectrometry.

Results: There was no association between serum total 25(OH)D and serum LDL-C. However, circulating 3-epi-25(OH)D 3 was negatively related to serum LDL-C $(r=-0.077, P<0.05)$, while no such association was found for non-epimeric $25(\mathrm{OH}) \mathrm{D}_{3}(r=0.030, P=0.33)$. On the other hand, both 3-epi-25(OH) $\mathrm{D}_{3}(r=0.175$, $P<0.001)$ and non-epimeric $25(\mathrm{OH}) \mathrm{D}_{3}(r=0.142, P<0.001)$ were positively related to serum triglyceride (TRIG) levels. In multiple linear regression models with age, gender, body mass index, urban residence, education, hypertension and education as covariates, it was found that 3-epi-25(OH) $\mathrm{D}_{3}$ was independently associated with serum LDL-C (beta $=-0.12, P<0.01$ ), while non-epimeric $25(\mathrm{OH}) \mathrm{D}_{3}$ was positively related to LDL-C (beta $\left.=0.13, P=0.002\right)$. For TRIG, there were positive association with 3-epi-25(OH)D $($ beta $=0.27, P<0.001$ ) and negative association with non-epimeric $25(\mathrm{OH}) \mathrm{D}_{3}$ (beta $=-0.10, P=0.011$ ) independent of age, gender, urban resident and education.
\end{abstract}

Conclusions: There is a discrepant association of $25(\mathrm{OH}) \mathrm{D}$ levels with serum lipids according to $25(\mathrm{OH}) \mathrm{D}$ epimeric forms.

Keywords: Epimer, Vitamin D, Serum lipids

\section{Background}

Vitamin D deficiency is highly prevalent even in tropical countries $[1,2]$. Lower vitamin $\mathrm{D}$ status has been associated with a number of chronic diseases, including metabolic syndrome and cardiovascular disease [3]. With

\footnotetext{
* Correspondence: laor.cha@mahidol.ac.th

${ }^{1}$ Department of Medicine, Ramathibodi Hospital, Mahidol University, Bangkok 10400, Thailand

${ }^{3}$ Division of Endocrinology and Metabolism, Department of Medicine, Faculty of Medicine Ramathibodi Hospital, Mahidol University, Rama 6th Road, Bangkok 10400, Thailand

Full list of author information is available at the end of the article
}

regard to cardiovascular disease, vitamin $\mathrm{D}$ has been shown in both cross-sectional and observational studies to be related to its occurrence [4] and associated mortality. The causality of vitamin D in this regard, as well as the underlying mechanisms involved, are still undetermined. For dyslipidemia, vitamin D deficiency has also been associated with higher levels of low-density lipoprotein cholesterol in a number of studies, but with inconsistent results from clinical trials [5].

The metabolism and action of vitamin D are complex, and this may underlie the incongruence found among 
studies. C-3 epimers of vitamin D metabolites are present in human circulation [6]. The biological functions of the epimers as compared to native vitamin D are not entirely settled; 3-epi-1 $\alpha, 25$-dihydroxyvitamin D $\left(25(\mathrm{OH})_{2} \mathrm{D}\right)$ binds to the vitamin $\mathrm{D}$ receptor with less affinity compared with its non-epimeric form [7]. However, 3-epi-1 $\alpha, 25(\mathrm{OH})_{2} \mathrm{D}$ suppresses parathyroid hormone to a similar degree to its non-epimeric counterpart [8]. It is unknown at present how C-3 epimers of vitamin D metabolites and lipid metabolism are related. Toward this end, we explored in the present study the relative importance of 3-epi-25(OH)D as compared with the nonepimeric form in their relationship to serum lipid levels.

\section{Methods}

\section{Study population}

This study used a subsample of 1068 participants who were randomly selected by computer-generated random numbers from the Thai $4^{\text {th }}$ National Health Examination Survey (NHES IV), conducted from August 2008 through March 2009 by the National Health Examination Survey Office, Health Systems Research Institute, Thailand, with a sample size of 21,960 Thai individuals. Details of sampling methods have been described previously [9]. Briefly, participants were randomly selects from 21 provinces in four regions of Thailand and the city of Bangkok. The present study drew on a subsample of the data by dividing the total sample into 24 strata based on sex, area of residence (urban or rural for each of the four geographic regions and Bangkok, which was regarded as an urban area only) and age-specific groups $(15-29,30-44,45-59,60-69,70-79$ and $\geq 80$ years of age). In each stratum, serum samples were randomly selected using statistical software from each region and Bangkok; ultimately, a total of 1068 Thais were sampled. Demographic data were collected by interviewers. Weight and height were measured by trained field staff using standard procedures. Body mas index (BMI) was calculated as weight in kilograms divided by the square of height in meters. Venous blood samples were obtained from participants in the moring after overnight fast. Fasting plasma glucose was measure on the same day of field data collection. Fasting serum samples were kept at $-80{ }^{\circ} \mathrm{C}$ before analyses. This study complied with the Declaration of Helsinki. It was also approved by the ethics committee of Ramathibodi Hospital. All subjects gave informed consent prior to the study.

\section{Definition of diabetes and hypertension}

Diabetes was defined as a previous diagnosis of diabetes by a physician and having taken hypoglycemic medication during the prior 2 weeks, or with fasting plasma glucose at the time of the survey $\geq 126 \mathrm{mg} / \mathrm{dL}$.
Hypertension was defined as mean systolic blood pressure equal to or greather than $140 \mathrm{~mm} / \mathrm{Hg}$ or mean diastolic blood pressure equal to or greater than $90 \mathrm{mmHg}$ or on medication to lower blood pressure in the past two weeks.

\section{Serum 25-hydroxyvitamin $D(25(\mathrm{OH}) \mathrm{D})$ measurement}

All vitamin D metabolites were analyzed by LC-MS/MS with an Agilent 1260 Infinity liquid chromatograph (Agilent Technologies, Waldbronn, Germany) coupled to a QTRAP $^{\circ} 5500$ tandem mass spectrometer (AB SCIEX, Foster City, CA, USA) using a MassChrom ${ }^{\circ}$ 25-OHVitamin D3/D2 in serum/plasma reagent kit including a 3-epi-25-OH-Vitamin D3/D2 upgrade diagnostics kit (Chromsystems, Munich, Germany). All analyte values of the calibrator and control were traceable to certified substances and standard reference materials of the National Institute of Standards and Technology. The summation of serum $25(\mathrm{OH}) \mathrm{D}_{3}, 25(\mathrm{OH}) \mathrm{D}_{2}, 3$-epi$25(\mathrm{OH}) \mathrm{D}_{3}$ and 3-epi-25(OH) $\mathrm{D}_{2}$ was used to reflect vitamin $\mathrm{D}$ status. The inter-assay and intra-assay coefficients of variation of total serum 25(OH)D level were 6.2 and $9.3 \%$, respectively.

\section{Biochemical measurement}

Serum cholesterol, low-density lipoprotein cholesterol (LDL-C), high-density lipoprotein cholesterol (HDL-C) and triglyceride (TRIG) levels were analyzed on an automated biochemical analyzer (Dimension RxL; Dade Behring, USA).

\section{Statistical analyses}

Data were expressed as mean \pm SD for normal distribution or median and range for non-normal distribution. The relative 3-epimer contribution (\%) was used to express the amount of 3-epimer-25(OH)D as a percentage of total $25(\mathrm{OH}) \mathrm{D}$ (the sum of $25(\mathrm{OH}) \mathrm{D}$ and 3-epi25(OH)D). The Kolmogorov-Smirnov test was used to test for normality. A logarithmic transformation was performed when the data did not follow a normal distribution. Mann-Whitney U test was used for comparisons of differences between two independent groups. Correlations between two parameters were estimated by using Spearman's rank correlation coefficient. Multiple linear regression models were used for assessing potential associated factors. A $P$ value less than 0.05 was considered statistically significant. All analyses were performed using Stata Statistical Software, Release 12 (StataCorp, College Station, TX, USA).

\section{Results}

Clinical characteristics of the study population are detailed in Table 1 . Half of the samples were males and $53 \%$ of all subjects resided in urban. Overll, mean age 
Table 1 Clinical Characteristics of the Study Population $(n=1068)$

\begin{tabular}{|c|c|}
\hline Characteristics & Mean $\pm S D$, or $\%$ \\
\hline Age, years & $53.4 \pm 22.3$ \\
\hline Male & $49.8 \%$ \\
\hline Urban & $53.9 \%$ \\
\hline Weight, kg & $57.8 \pm 12.7$ \\
\hline \multicolumn{2}{|l|}{ Education } \\
\hline$<$ Primary & $8.8 \%$ \\
\hline Primary & $56.4 \%$ \\
\hline Secondary & $28.5 \%$ \\
\hline University & $6.5 \%$ \\
\hline Height, cm & $158.0 \pm 8.5$ \\
\hline $\mathrm{BMI}, \mathrm{kg} / \mathrm{m}^{2}$ & $23.1 \pm 4.6$ \\
\hline \multicolumn{2}{|l|}{$\mathrm{BMI} \geq 25 \mathrm{~kg} / \mathrm{m}^{2}$} \\
\hline No & $71.2 \%$ \\
\hline Yes & $28.8 \%$ \\
\hline \multicolumn{2}{|l|}{ Hypertension } \\
\hline No & $69.3 \%$ \\
\hline Yes & $30.7 \%$ \\
\hline \multicolumn{2}{|l|}{ Diabetes } \\
\hline No & $93.3 \%$ \\
\hline Yes & $6.7 \%$ \\
\hline Cholesterol (mmol/L) & $5.3 \pm 1.2$ \\
\hline LDL-C (mmol/L) & $3.4 \pm 1.0$ \\
\hline $\mathrm{HDL}-\mathrm{C}(\mathrm{mmol} / \mathrm{L})$ & $1.2 \pm 0.3$ \\
\hline Triglycerides (mmol/L) & $1.6 \pm 1.1$ \\
\hline Serum non-epimeric $25(\mathrm{OH}) \mathrm{D}_{3}(\mathrm{nmol} / \mathrm{L})$ & $71.9 \pm 20.2$ \\
\hline Serum non-epimeric $25(\mathrm{OH}) \mathrm{D}_{2}(\mathrm{nmol} / \mathrm{L})$ & $1.7 \pm 2.2$ \\
\hline Serum 3-epi-25(OH)D $\mathrm{D}_{3}(\mathrm{nmol} / \mathrm{L})$ & $5.5 \pm 3.0$ \\
\hline Serum 3-epi-25(OH)D 2 (nmol/L) & $0.19 \pm 0.07$ \\
\hline Total 25(OH)D (nmol/L) & $79.4 \pm 22.5$ \\
\hline
\end{tabular}

Table 2 Association between Serum Lipids and 25(OH)D Levels

\begin{tabular}{|c|c|c|c|c|c|c|}
\hline & & Total 25(OH)D & 3-epi-25(OH)D $\mathrm{D}_{3}$ & Non-epimeric $25(\mathrm{OH}) \mathrm{D}_{3}$ & 3-epi-25(OH)D $\mathrm{D}_{2}$ & Non-epimeric $25(\mathrm{OH}) \mathrm{D}_{2}$ \\
\hline \multirow[t]{2}{*}{ Cholesterol } & $r=$ & 0.061 & -0.008 & 0.064 & -0.015 & 0.001 \\
\hline & $P=$ & 0.045 & 0.786 & 0.036 & 0.616 & 0.962 \\
\hline \multirow[t]{2}{*}{ LDL-C } & $r=$ & 0.016 & -0.077 & 0.030 & -0.032 & -0.062 \\
\hline & $P=$ & 0.604 & 0.012 & 0.328 & 0.289 & 0.044 \\
\hline \multirow[t]{2}{*}{$\mathrm{HDL}-\mathrm{C}$} & $r=$ & -0.063 & -0.072 & -0.067 & 0.052 & 0.035 \\
\hline & $P=$ & 0.039 & 0.018 & 0.030 & 0.088 & 0.254 \\
\hline \multirow[t]{2}{*}{ Triglycerides } & $r=$ & 0.161 & 0.175 & 0.142 & -0.023 & 0.115 \\
\hline & $P=$ & $<0.001$ & $<0.001$ & $<0.001$ & 0.456 & $<0.001$ \\
\hline
\end{tabular}

was 53 year old and mean 25(OH)D was $79.4 \mathrm{nmol} / \mathrm{L}$. More than half $(56.4 \%)$ of the subjects had primary education and $35 \%$ had secondary education level or above. $28.8 \%$ of the participants had BMI $>=25 \mathrm{~kg} / \mathrm{m}^{2}$. Hypertension and type 2 diabetes were found in 30.7 and $6.7 \%$ of the subjects, respectively. The relative abundance of 3-epi-25(OH)D compared with total 25(OH)D (relative 3-epimer contribution) ranging from 1.74 to $24.49 \%$, with a median value of $6.48 \%$. Subjects with vitamin D insufficiency, as defined by total $25(\mathrm{OH}) \mathrm{D}$ levels less than $75 \mathrm{nmol} / \mathrm{L}$, had lower the relative 3epimer contribution compared to those with vitamin D sufficiency (median 6.34\%, ranged 1.74-14.15\% and median 6.70, ranged $2.56-24.49$, repectively) $(P=0.001)$. Table 2 shows the association between serum lipid and $25(\mathrm{OH}) \mathrm{D}$ levels. There was no association between serum total 25(OH)D and serum LDL-C. However, circulating 3-epi-25(OH)D $\mathrm{D}_{3}$ was negatively related to serum LDL-C $(r=-0.077, P<0.05)$, while no such association was found for non-epimeric $25(\mathrm{OH}) \mathrm{D}_{3}(r=0.030$, $P=0.33)$. On the other hand, both 3 -epi-25(OH) $\mathrm{D}_{3}(r=$ $0.175, P<0.001)$ and non-epimeric $25(\mathrm{OH}) \mathrm{D}_{3}(r=0.142$, $P<0.001)$ were positively related to serum TRIG levels. In multiple linear regression models with age, gender, BMI, urban residence, education, hypertension and diabetes as covariates, it was found that 3-epi$25(\mathrm{OH}) \mathrm{D}_{3}$ was independently associated with serum LDL-C (beta $=-0.12, \quad P<0.01$ ), while non-epimeric $25(\mathrm{OH}) \mathrm{D}_{3}$ was positively related to LDL-C (beta $=$ $0.13, P=0.002$ ) (Table 3$)$. For TRIG, there were positive association with 3 -epi-25(OH)D $\mathrm{D}_{3}$ (beta $=0.27, P<$ $0.001)$ and negative association with non-epimeric $25(\mathrm{OH}) \mathrm{D}_{3}, \quad($ beta $=-0.10, \quad P=0.011)$ independent of age, gender, urban resident and education.

\section{Discussion}

In the present study using a subsample from a nationally representatively survey, we demonstrated that 3-epi$25(\mathrm{OH}) \mathrm{D}$ was negatively related to serum LDL-C but positively related to serum TRIG. The association was not likely to be affected by some underlying chronic 
Table 3 Multiple Linear Regression According to Predictive Factors and Serum Lipids

\begin{tabular}{|c|c|c|c|c|c|c|c|c|}
\hline \multirow[t]{2}{*}{ Variable } & \multicolumn{2}{|c|}{ Cholesterol } & \multicolumn{2}{|l|}{ LDL-C } & \multicolumn{2}{|l|}{$\mathrm{HDL}-\mathrm{C}$} & \multicolumn{2}{|c|}{ Triglycerides } \\
\hline & Beta & $P$-value & Beta & $P$-value & Beta & $P$-value & Beta & $P$-value \\
\hline Age & 0.22 & $<0.001$ & 0.23 & $<0.001$ & -0.08 & 0.075 & 0.07 & 0.1061 \\
\hline Male & -0.17 & $<0.001$ & -0.16 & $<0.001$ & -0.17 & $<0.001$ & 0.04 & 0.211 \\
\hline BMI & 0.17 & $<0.001$ & 0.15 & $<0.001$ & -0.22 & $<0.001$ & 0.20 & $<0.001$ \\
\hline Urban/rural & 2.33 & 0.401 & 0.02 & 0.636 & 0.10 & 0.002 & -0.03 & 0.344 \\
\hline Education & 0.44 & 0.287 & 0.04 & 0.367 & 0.14 & $<0.001$ & -0.05 & 0.222 \\
\hline Hypertension & 7.53 & 0.024 & 0.01 & 0.788 & 0.03 & 0.471 & 0.15 & $<0.001$ \\
\hline Diabetes & 0.42 & 0.940 & -0.03 & 0.281 & -0.03 & 0.394 & 0.07 & 0.035 \\
\hline 3-epi-25(OH) $\mathrm{D}_{3}$ & -0.02 & 0.987 & -0.12 & 0.003 & 0.05 & 0.170 & 0.27 & $<0.001$ \\
\hline Non-epimeric $25(\mathrm{OH}) \mathrm{D}_{3}$ & 0.10 & 0.035 & 0.13 & 0.002 & 0.01 & 0.841 & -0.10 & $=0.011$ \\
\hline
\end{tabular}

diseases such as obesity, diabetes and hypertension in particular, as they were controlled in the regression model. Such a relationship was not readily apparent with non-epimeric 25(OH)D levels, or even reversed. With regard to the opposite effect of $3-\mathrm{epi}-25(\mathrm{OH}) \mathrm{D}_{3}$ vs. its non-epimeric counterpart on serum LDL-C from multiple regression analysis, it is possible that 3-epi$25(\mathrm{OH}) \mathrm{D}_{3}$ may exert different influence on LDL-C metabolism from that of $25(\mathrm{OH}) \mathrm{D}_{3}$. However, since 3-epi$25(\mathrm{OH}) \mathrm{D}_{3}$ and the non-epimeric $25(\mathrm{OH}) \mathrm{D}_{3}$ levels were correlated, it is also likely the discrepant finding may be a result of multicollinearilty making the independent effect of each of these metabolites hard to determine in the statistical analysis. For the different direction of association between 3-epi-25(OH)D with LDL-C and TRIG, the underlying reason for the observation is not entirely. However, since hepatic lipase is responsible for the conversion of triglyceride rich very low density lipoprotein to intermediate density lipoprotein and hence LDL, it is conceivable that 3 -epi-25(OH)D might reduce the acitivity of hepatic lipase rendering lower LCL-C levels but higher TRIG levels.

Although the causal influence of vitamin D in the determination of serum lipids cannot be concluded from our study, the findings suggest that the effect of vitamin $\mathrm{D}$ on lipid metabolism, if any, is likely to be partly dependent on the epimeric forms of vitamin D metabolites. Clinical studies looking at the independent effect of $25(\mathrm{OH}) \mathrm{D}$ epimers are scarce. Our finding is in keeping with at least one recent clinical study showing that vitamin D epimers, compared with total or non-epimeric forms of $25(\mathrm{OH})$, are more related to a number of disease states including type 2 diabetes, rheumatoid arthritis and Alzheimer's disease [10]. Dyslipidemia, however, was not assessed in the study. With regard to bone health, a more recent study in rodents showed that the $C-3 \alpha$ vitamin $D$ epimer increases with higher doses of vitamin D supplementation, without influencing bone mass [11]. In addition, in healthy term infants who received a vitamin D supplement, it was found that 3-epi$25(\mathrm{OH}) \mathrm{D}_{3}$ was not associated with body composition [12].

Although the role of LDL-C in atherosclerosis is well established, the role of raised TRIG in cardiovascular disease is controversial. The adverse effect of hypertriglyceridemia on cardiovascular disease, if any, is more likely to occur with serum triglycerides in the mild to middle range, since at higher levels the lipoproteins could be too large to enter the arterial intima [13, 14]. However, genetic studies, including those using the Mendelian randomization approach, have suggested that triglyceride-rich lipoproteins are a causal risk factor of cardiovascular disease $[15,16]$. The effect of vitamin D on cardiovascular disease and mortality has been suggested. A recent meta-analysis showed the influence of vitamin $\mathrm{D}_{3}$ on mortality, while vitamin $\mathrm{D}_{2}$ did not appear to have any effect [17]. A more recent systematic review also demonstrated the effect of vitamin $\mathrm{D}$ on mortality associated with various causes, including those related to cardiovascular disease and cancer [18]. In addition, Ciccone et al., has found a significant correlation of vitamin D deficiency with mortality for major cardiovascular events such as heart failure, myocardial infarction, sudden cardiac death, stroke, atrial fibrillation, and peripheral vascular disease [19]. The causal role of vitamin $\mathrm{D}$, however, in cardiovascular diseases and others is controversial [20]. Likewise, the causal relationship between vitamin $\mathrm{D}$ epimers and dyslipidemia as well as other disease states is unclear. Nevertheless, there are indications of biological possibility. The epimer 3-epi-25(OH) $D_{3}$ can undergo $1 \alpha$-hydroxylation to form 3-epi-1,25(OH $)_{2} \mathrm{D}_{3}$, which can bind to the vitamin $\mathrm{D}$ receptor and activate gene transcription [21]. It appears that 3-epi-1,25(OH $)_{2} \mathrm{D}_{3}$ is nearly potent as $1,25(\mathrm{OH})_{2} \mathrm{D}_{3}$ in suppressing parathyroid hormone secretion but has significantly reduced calcemic effects $[8,22]$.

The observed correlation between 3-epi-25(OH)D and serum lipids in the present study may be part of the underlying basis for the association between vitamin $\mathrm{D}$ 
status and cardiovascular health. A small study found an association between vascular health indices and serum total and free 25(OH)D in adolescents [23].

Despite the promising effect of vitamin D on serum lipids, interventional trials with vitamin $\mathrm{D}$ have generally failed to demonstrate a causal association. A number of previous studies have investigated the relationship between vitamin D status and serum lipids. For example, calcium/vitamin supplementation was found to have a favorable effect on serum lipids in the Women's Health Initiative study [24]. A small clinical trial using vitamin D-fortified skimmed milk found a reduction in blood pressure but no beneficial effect of the intervention on serum lipids [25]. However, blood pressure reduction was not found in another study of vitamin D supplementation [26]. Besides the probable difference in study design and study populations, it is likely that betweensubject differences in the proportion of the epimeric versus non-epimeric forms of vitamin $\mathrm{D}$ after supplementation may partly be accountable for the inconsistent results. Further clinical trials looking at the effect of vitamin D should probably include the assessment of vitamin D epimers.

A number of limitations are present in this study. The study was cross-sectional in nature and the causative role of vitamin D epimers, if any, could not be readily determined. Moreover, although none of the subjects in the present study were taking lipid-lowering agents, data regarding other concurrent medications or supplements, dietary intake of vitamin $\mathrm{D}$ and food consumption which may influence serum lipids or vitamin D status and the association were not available. Further studies controlling for such variables are therefore warranted.

\section{Conclusion}

This is the first report of the discrepant association of $25(\mathrm{OH}) \mathrm{D}$ levels with serum lipids according to $25(\mathrm{OH}) \mathrm{D}$ epimeric forms. The relative amount of 3-epi- versus non-epimeric $25(\mathrm{OH}) \mathrm{D}$ after vitamin D supplementation may be attributable to the discrepant findings among clinical trials.

\section{Abbreviations}

25(OH)D: 25-hydroxyvitamin D; BMI: Body mass index; HDL-C: High-density lipoprotein cholesterol ; LDL-C: Low density lipoprotein-cholesterol; TRIG: Triglyceride

\section{Acknowledgements}

The $4^{\text {th }}$ Thai National Health Examination Survey (NHESIV) was conducted by the National Health Examination Survey Office, Health Systems Research Institute, Thailand.

\section{Funding}

This study was supported by the National Science and Technology Development Agency.

\section{Availability of data and materials}

The datasets supporting the conclusions of this article are available upon request.

\section{Authors' contributions}

The authors of this manuscript have contributed with following: conception and design of the study (LC, WA, BO), analysis of data (LC, KS), interpretation of data (LC, WA, BO), drafting the article (LC, KS, BO). All authors read and approved the final manuscript.

\section{Competing interests}

The authors declare that they have no competing interests.

Consent for publication

Not applicable.

\section{Ethics approval and consent to participate}

This study complied with the Declaration of Helsinki. It was also approved by the ethics committee of Ramathibodi Hospital. All subjects gave informed consent prior to the study.

\section{Author details}

'Department of Medicine, Ramathibodi Hospital, Mahidol University, Bangkok 10400, Thailand. ${ }^{2}$ Department of Community Medicine, Ramathibodi Hospital, Mahidol University, Bangkok 10400, Thailand. ${ }^{3}$ Division of Endocrinology and Metabolism, Department of Medicine, Faculty of Medicine Ramathibodi Hospital, Mahidol University, Rama 6th Road, Bangkok 10400, Thailand.

Received: 23 June 2016 Accepted: 13 September 2016

Published online: 15 September 2016

\section{References}

1. Chailurkit L, Aekplakorn W, Ongphiphadhanakul B. Regional variation and determinants of vitamin D status in sunshine-abundant Thailand. BMC Public Health. 2011;11:853.

2. Lips P. Vitamin D, status and nutrition in Europe and Asia. J Steroid Biochem Mol Biol. 2007;103:620-5.

3. Holick MF. Vitamin D: importance in the prevention of cancers, type 1 diabetes, heart disease, and osteoporosis. Am J Clin Nutr. 2004;79:362-71.

4. Wang TJ, Pencina MJ, Booth SL, Jacques PF, Ingelsson E, Lanier K, Benjamin EJ, D'Agostino RB, Wolf M, Vasan RS. Vitamin D deficiency and risk of cardiovascular disease. Circulation. 2008;117:503-11.

5. Challoumas D. Vitamin D, supplementation and lipid profile: what does the best available evidence show? Atherosclerosis. 2014;235:130-9.

6. Bailey D, Veljkovic K, Yazdanpanah M, Adeli K. Analytical measurement and clinical relevance of vitamin D(3) C3-epimer. Clin Biochem. 2013;46:190-6.

7. Kamao M, Tatematsu S, Hatakeyama S, Sakaki T, Sawada N, Inouye K, Ozono K, Kubodera N, Reddy GS, Okano T. C-3 epimerization of vitamin D3 metabolites and further metabolism of C-3 epimers: 25-hydroxyvitamin D3 is metabolized to 3-epi-25-hydroxyvitamin D3 and subsequently metabolized through C-1alpha or C-24 hydroxylation. J Biol Chem. 2004;279: 15897-907.

8. Brown AJ, Ritter C, Slatopolsky E, Muralidharan KR, Okamura WH, Reddy GS. 1Alpha,25-dihydroxy-3-epi-vitamin D3, a natural metabolite of 1alpha,25dihydroxyvitamin D3, is a potent suppressor of parathyroid hormone secretion. J Cell Biochem. 1999;73:106-13.

9. Aekplakorn W, Sangthong R, Kessomboon P, Putwatana P, Inthawong R, Taneepanichskul S, Sritara P, Sangwatanaroj S, Chariyalertsak S, National Health Examination Survey IVsg. Changes in prevalence, awareness, treatment and control of hypertension in Thai population, 2004-2009: Thai National Health Examination Survey III-IV. J Hypertens. 2012;30:1734-42.

10. Shah I, Petroczi A, Naughton DP. Exploring the role of vitamin D in type 1 diabetes, rheumatoid arthritis, and Alzheimer disease: new insights from accurate analysis of 10 forms. J Clin Endocrinol Metab. 2014;99:808-16.

11. Bianchini C, Lavery P, Agellon S, Weiler HA. The generation of C-3alpha epimer of 25-hydroxyvitamin $d$ and its biological effects on bone mineral density in adult rodents. Calcif Tissue Int. 2015;96:453-64.

12. Hazell TJ, Gallo S, Berzina L, Vanstone CA, Rodd C, Weiler HA. Plasma 25-hydroxyvitamin $\mathrm{D}$, more so than its epimer, has a linear relationship 
to leaner body composition across infancy in healthy term infants. Appl Physiol Nutr Metab. 2014;39:1137-43.

13. Nordestgaard BG, Zilversmit DB. Large lipoproteins are excluded from the arterial wall in diabetic cholesterol-fed rabbits. J Lipid Res. 1988;29:1491-500.

14. Nordestgaard BG, Stender S, Kjeldsen K. Reduced atherogenesis in cholesterol-fed diabetic rabbits. Giant lipoproteins do not enter the arterial wall. Arteriosclerosis. 1988;8:421-8.

15. Varbo A, Benn M, Tybjaerg-Hansen A, Jorgensen AB, Frikke-Schmidt $R$, Nordestgaard BG. Remnant cholesterol as a causal risk factor for ischemic heart disease. J Am Coll Cardiol. 2013;61:427-36.

16. Jorgensen AB, Frikke-Schmidt R, West AS, Grande P, Nordestgaard BG Tybjaerg-Hansen A. Genetically elevated non-fasting triglycerides and calculated remnant cholesterol as causal risk factors for myocardial infarction. Eur Heart J. 2013;34:1826-33.

17. Schottker B, Jorde R, Peasey A, Thorand B, Jansen EH, Groot L, Streppel M, Gardiner J, Ordonez-Mena JM, Perna L, et al. Vitamin D and mortality: metaanalysis of individual participant data from a large consortium of cohort studies from Europe and the United States. BMJ. 2014;348:93656.

18. Chowdhury R, Kunutsor S, Vitezova A, Oliver-Williams C, Chowdhury S, Kiefte-de-Jong JC, Khan H, Baena CP, Prabhakaran D, Hoshen MB, et al. Vitamin $D$ and risk of cause specific death: systematic review and metaanalysis of observational cohort and randomised intervention studies. BMJ. 2014;348:91903

19. Ciccone MM, Zito A, Dentamaro I, Vestito D, Scicchitano P, lacoviello M, De Pergola G, Devito F. Vitamin D deficiency and cardiovascular diseases. G Ital Cardiol (Rome). 2015;16:16-20

20. Jorde R, Grimnes G. Vitamin D and health: the need for more randomized controlled trials. J Steroid Biochem Mol Biol. 2015;148:269-74.

21. Rehan VK, Torday JS, Peleg S, Gennaro L, Vouros P, Padbury J, Rao DS, Reddy GS. 1Alpha,25-dihydroxy-3-epi-vitamin D3, a natural metabolite of 1alpha,25-dihydroxy vitamin D3: production and biological activity studies in pulmonary alveolar type II cells. Mol Genet Metab. 2002;76:46-56.

22. Fleet JC, Bradley J, Reddy GS, Ray R, Wood RJ. 1 alpha,25-(OH)2-vitamin D3 analogs with minimal in vivo calcemic activity can stimulate significant transepithelial calcium transport and mRNA expression in vitro. Arch Biochem Biophys. 1996;329:228-34.

23. Ashraf AP, Alvarez JA, Dudenbostel T, Calhoun D, Griffin R, Wang X, Hanks $\sqcup$, Gower BA. Associations between vascular health indices and serum total, free and bioavailable 25-hydroxyvitamin D in adolescents. PLoS One. 2014;9: e114689.

24. Schnatz PF, Jiang X, Vila-Wright S, Aragaki AK, Nudy M, O'Sullivan DM, Jackson R, LeBlanc E, Robinson JG, Shikany JM, et al. Calcium/vitamin D supplementation, serum 25-hydroxyvitamin D concentrations, and cholesterol profiles in the Women's Health Initiative calcium/vitamin D randomized trial. Menopause. 2014;21:823-33.

25. Toxqui L, Blanco-Rojo R, Wright I, Perez-Granados AM, Vaquero MP. Changes in blood pressure and lipid levels in young women consuming a vitamin D-fortified skimmed milk: a randomised controlled trial. Nutrients. 2013;5: 4966-77.

26. Witham MD, Ireland S, Houston JG, Gandy SJ, Waugh S, Macdonald TM, Mackenzie IS, Struthers AD. Vitamin D therapy to reduce blood pressure and left ventricular hypertrophy in resistant hypertension: randomized, controlled trial. Hypertension. 2014;63:706-12.

\section{Submit your next manuscript to BioMed Central and we will help you at every step:}

- We accept pre-submission inquiries

- Our selector tool helps you to find the most relevant journal

- We provide round the clock customer support

- Convenient online submission

- Thorough peer review

- Inclusion in PubMed and all major indexing services

- Maximum visibility for your research

Submit your manuscript at www.biomedcentral.com/submit

) Biomed Central 